\title{
New ways of learning to fight fires? Learning processes and contradictions in distance and on-campus firefighter training in Sweden
}

\author{
Robert Holmgren \\ Umeå University, Sweden
}

\begin{abstract}
This article reports on findings from a comparative study on firefighter students' learning processes in a technology-supported distance training course and a traditional campus training course in Sweden. Based on student interviews and observations of exercises, the article aims to describe and analyse the impact on learning processes when exerciseoriented teaching takes place in a technology-supported learning environment instead of face to face on campus. Drawing on the concept of contradiction in activity theory, the findings indicate that distance students encounter several dilemmas and conflicts related to low instructor presence, ambiguities regarding learning requirements and division of labor, as well as shortcomings in the technologies offered. However, the distance students tend to develop strategies for dealing with these contradictions, resulting in the development of self-directed learning and more learner-centered approaches, while the campus students rely to a greater extent on traditional, instructor-centered teaching. During the 2-year training course, however, it appears the established norms and conventions of teaching and learning which characterise the campus mode, counteract changes in the distance mode. The technology-supported learning process with its focus on exercise preparation is thus gradually normalised in the direction of the campus mode, and its face -to-face, instructorled and exercise-oriented learning process.
\end{abstract}

\section{Introduction}

Technology-supported distance learning is an increasingly common study mode in practically oriented professional training courses. In line with this development, the campus-based firefighter training in Sweden was supplemented in 2008 with a distance mode, enabling students to do more than $75 \%$ of their studies at home. While the campus mode is characterised by traditional face-to-face-based learning activities where theoretically-oriented preparations are integrated with practical exercises, the distance mode is designed as an online-based theoretically-oriented preparation phase that is separate from the oncampus exercises. In the light of this radical educational change, and given that research into other educational fields has shown that contradictions may arise in online-based learning environments (cf. Dippe, 2006; Choi \& Kang, 2010), it seemed relevant to complement this body of knowledge with a study of a practically-oriented training course. Drawing on the key concept of contradiction in activity theory (Engeström, 1987, 2001) and based on a comparative approach, this article draws attention to how the firefighter students' learning processes are affected and transformed when technology-supported distance learning is used in the educational practice. In order to increase the understanding of these processes, interviews with students from both the early and the late stages of the training programme, and from both distance and campus modes have been included in the study, as well as observations of exercises on the training grounds.

In another study dealing with the instructor role in Swedish firefighter training (Holmgren, 2014), it was shown that several contradictions may arise when a traditionally strong instructor role based on professional skills and instructor-centered teaching on training grounds clashes with an online landscape with its affordances and constraints. It was reported that instructors' well established exercise-oriented teaching-box does not fit in the online environment and that they feel that they lose control of the students' learning process, lack supporting structures and tend to prioritise the needs of the campus mode at the expense of those of the distance mode. Conclusions drawn are that the implementation of technology-supported distance learning affects the instructor role only marginally and that personal motives and structural barriers contribute to the preservation of the traditional instructor role.

Other studies on learning in practical vocational training that compare on-campus and distance modes are largely focused on learning outcomes (cf. Collins \& Pascerella, 2003; Campbell, Gibson, Hall, Richards, \& Callery, 2008). The dominant conclusion seems to be that the choice of study mode has no effect on the 
students' learning. However research focusing on learning processes seems to be in its infancy, in particular studies of how learning processes are influenced and transformed by the use of digital technologies. A review of the research literature shows that the majority of studies on learning processes and the use of learning technologies have been carried out within higher education and vocational education, such as medical and teacher training programs. In view of the current knowledge gaps in the field of vocational training, it appears relevant to expand the understanding of how learning processes are influenced and transformed when technology-supported distance learning are introduced into exercise training courses.

The key questions that this study aims to answer are:

- What contradictions can be identified in distance and on-campus students' learning processes and how do the students handle these?

- How are the learning processes of firefighter students affected when a large part of their training takes place in a technology-supported distance training environment instead of face to face on campus?

\section{Learning processes supported by digital technologies: A student perspective}

A review of the literature shows that only very few studies have been performed on learning processes and technology-supported distance learning in firefighter training. A broader review that also includes other programs suggests that five themes are relevant to this study.

The first theme deals with the social dimension of the learning process and is often referred to in terms of Participation in learning communities. An emerging consensus seems to be that learning communities can be created in online environments, i.e. students who, connected via technology-mediated communication tools, actively collaborate in learner-centered activities with the aim of creating knowledge (Shea, 2006). In these studies, the significance of active participants and inclusive approaches are emphasised, since the dialogue with instructors is often sparse (Olofsson, 2007). It is also shown that the students' different experiences can be utilised in online discussions and thus contribute to collective and self-directed learning (Maxfield \& Fisher 2011). However, it has also been observed that reluctance to collaboration can occur, resulting in online participants seeing themselves as isolated from each other (Kian-Sam \& Lee, 2008). Moreover, Yang, Catterall, and Davis (2013) have shown that new vocational training students' participation in online learning activities may be limited and cause frustration as they experience difficulties with the online environment and balancing the demands of work and study.

The second theme, which is related to the first, is Students' need of support and instructor teaching presence. It has been shown that there is a relationship between how learning communities evolve and teachers' presence and behaviour in online environments. For example, it has been demonstrated that students' sense of learning community is clearly linked to their recognition of course instructor's effective instructional design and directed facilitation, and that directed facilitation on the part of the instructor is a critical aspect for students' sense of connectedness and learning (Shea 2006). Important aspects seem to be that the students feel that the instructor creates a climate conducive to learning, keeps students on track and has the ability to diagnose student misperceptions. These conclusions are consistent with Sharpe, Beetham, Benfield, DeCicco and Lessner (2009), who have demonstrated how expected behaviours among students are modeled by the instructor, and with Kian-Sam and Lee (2008), who point to the importance of facilitators who can encourage higher order discussions.

The third theme is Comparisons between face-to-face learning and online/distance learning. These studies involve a broad range of aspects, from learning outcomes to students' experiences of the pros and cons of each educational mode. In studies with a focus on the latter, some salient and partly shared conclusions have been arrived at. For example, it has been found that online learning can be beneficial for the development of autonomous and flexible learning (Donovant, 2009; Paechter \& Maier, 2010), and that the lack of a sense of community and interaction with peers and instructors results in face-to-face learning being the preferred mode when common understanding is to be achieved and when interpersonal relationships need to be established (Paechter \& Maier, 2010). 
The fourth theme, Students' use of digital technologies and its impact on learning processes, can be found in, for example, the European Convention Educational Report (Redecker, Ala-Mutka, Bacigalupo, Ferrari, \& Punie, 2009), which is based on a review of 250 cases in European education and training. The report's findings reflect a strong belief in the potential of web-based technologies as enhancement agents of education and learning processes:

Learning 2.0 approaches support motivation, participation and reflection, empowering learners to develop self-directed learning skills, and helping them to better realise their personal potential. They give rise to new interaction patterns between and among students and teachers, changing the roles of participants in the learning process. (Redecker, AlaMutka, Bacigalupo, Ferrari, \& Punie, 2009, p. 70)

In other studies however, it has been demonstrated that implementation of digital technologies in education and training does not per se result in improved educational outcomes or new ways of studying. Instead, Kirkwood (2009) for example, shows that contextual factors such as students' perceptions and expectations of teaching and learning, institutional norms, values of teaching and assessment and the teachers' approach to teaching affect students' ways of using digital technologies in their studies. Price and Kirkwood (2010) who, based on the concept of technology-enhanced learning, have examined the evidence published in this field, report that while it is difficult to measure improvement, there are indications that improvements actually occur. However the evidence that supports these claims is tangential.

The conclusion that students' use of digital technologies can contribute to changes in the learning process has however been drawn in several studies. Conole, de Laat, Dillon, and Darby (2008) conclude in their multiple case study in four subject disciplines that students' use of digital technologies is pervasive throughout the learning process and that they are comfortable with working with multiple resources and tools simultaneously. Furthermore, their use is adapted to their personal needs and preferences and they are often part of a wider study community. Their use is also transboundary when it comes to learning and is not limited to specific times or places. Similar findings were also arrived at by Andrews and Tynan (2012) who describe distance students in terms of connected, mobile and resourceful individuals, and by de Laat and Conole (2008) who show that such students tend to become more critical users of technologies, more strategic in their way of learning and more inclined to communicate with one another and to share knowledge. Margaryan, Nicol, Littlejohn, and Trinder (2008) further demonstrate how students' use of technology tends to blur the boundaries between the public and private and between physical and virtual learning environments. They also point to a tendency towards an increasing mismatch between students' expectations of e-learning and institutional offerings of technologies. Taken together, these studies yield a picture of students' technology-supported learning processes as being characterised by ownership, personalisation and appropriation.

The fifth and final theme is Studies which from a student perspective analyse contradictions that may arise when digital technologies are used in educational contexts. For example Dippe (2006), who studied distance education for teacher students, states that contradictions may arise between how a training program is presented and how it is implemented. Institutional shortcomings in competence requirements for teachers and unclear division of responsibilities between students and teachers result in a distance learning environment characterised by absent teachers, deteriorating student work and expected online learning activities being replaced with face-to-face meetings. Furthermore contradictions between learners and tools and learners and objects have been identified in online courses in higher education by Karasavvidis (2009), and Choi and Kang (2010). Karasavvidis (2009) reports on varying degrees of use of online resources among students, where the pattern was that only materials needed for mandatory assignments were used. Choi and Kang (2010) demonstrated that students used ineffective methods, that resources were lacking and that students' lack of knowledge of the subject resulted in their being unable to find relevant information. Finally, in Liu and Schwen's (2006) studies of online courses in the MBA and in Antoniado's (2011) study of student-teachers' tele-collaboration, it is shown that contradictions may arise between the learners and the different activities they are involved in. For example, Liu and Schwen (2006) identified competing responsibilities among MBA learners, whose contributions in both studies and at work were expected to be of a high standard, which resulted in their giving priority to their work at the expense of optimised academic achievement and volunteer online communication. 


\section{Swedish firefighter training in brief}

The Swedish Civil Contingencies Agency (Myndigheten för Samhällsskydd och Beredskap) is responsible for firefighter training in Sweden. Its basic Accident Prevention Training Course (MSB, 2002) is given at two colleges. This training course, which qualifies successful candidates for employment in the municipal rescue services, has been radically reformed in recent years. In 2003 the course was extended from 15 to 80 weeks of study and a preventive Risk and safety module was introduced to complement the operative Fire and rescue module. In 2008 a parallel training structure with on-campus and distance modes was launched. While the campus mode is based on an integrated structure of classroom-based theoretical preparations followed by practical exercises, the structure of the distance mode is based on separate theory-based online studies and exercises on campus. The online studies are conducted via the course platform where teaching material can be distributed and discussions held in asynchronous question and discussion forums. In addition to the course platform, there is a web conferencing platform for synchronous communication. Approximately 30 campus and 30 distance students are admitted each semester at each college. In total the training program at the college under study at any time comprises approximately 240 students, some 20 regular instructors and several exercise instructors periodically hired from the rescue services for short periods of instruction. Current training statistics show that the majority of the students are men and that the differences in mean age and grade points between campus and distance students are marginal.

\section{Activity theory and the notion of contradiction as a theoretical framework}

This analysis is inspired by activity theory (AT) and its key concept of contradiction (Engeström, 1987, 2001). This theory is considered adequate for analysis of activities which accommodate the use of digital technologies (Kaptelinin \& Nardi, 2006) and to understand how the use of technologies can promote change in teaching and learning processes in education (Murphy \& Rodriguez-Manzaneres, 2008). Following Engeström (2001), contradictions are historically accumulated structuring tensions within and between activities, which create "disturbances and conflicts, but also innovative attempts to change the activity” (p.134). In an analysis based on the five principles of activity theory (Engeström, 2001), the activity itself constitutes the unit of analysis and takes into account its multi-voicedness and history; the members of the activity carry with them their life stories, and the activity also has a story which is embedded in tools, rules and conventions. Furthermore contradictions are considered to result in tensions, but also to be a driving force for transformation of activities. The final principle of expansive learning relates to possible changes in the activity that may be enabled if the object and motives of the activity are the subjects for reconceptualisation. Contradictions may thus promote change and lead to expansive learning. However unless transformation of the activity takes place, change may not be forthcoming. Counteracting aspects may be for example, difficulties in identifying, acknowledging and openly discussing the contradictions in an activity (Engeström, 1993).

In this study the activity is restricted to two training courses, whose main goal is that the students (subjects) should acquire the knowledge and skills needed for fire-fighting and rescue operations (object). While the student groups are trained in accordance with the same course criteria and exercise-oriented guidelines, the preparation and exercise structure (rules) and the mediating teaching tools (tools) are different. In addition the students participate together with their respective course instructors in separate communities, online-based or campus-based, and finally the activity is regulated by the division of labor (division of tasks, responsibilities, roles) developing within each course. Figure 1 shows the analysis unit and its elements and relationships. 


\section{Firefighter training course as an activity}

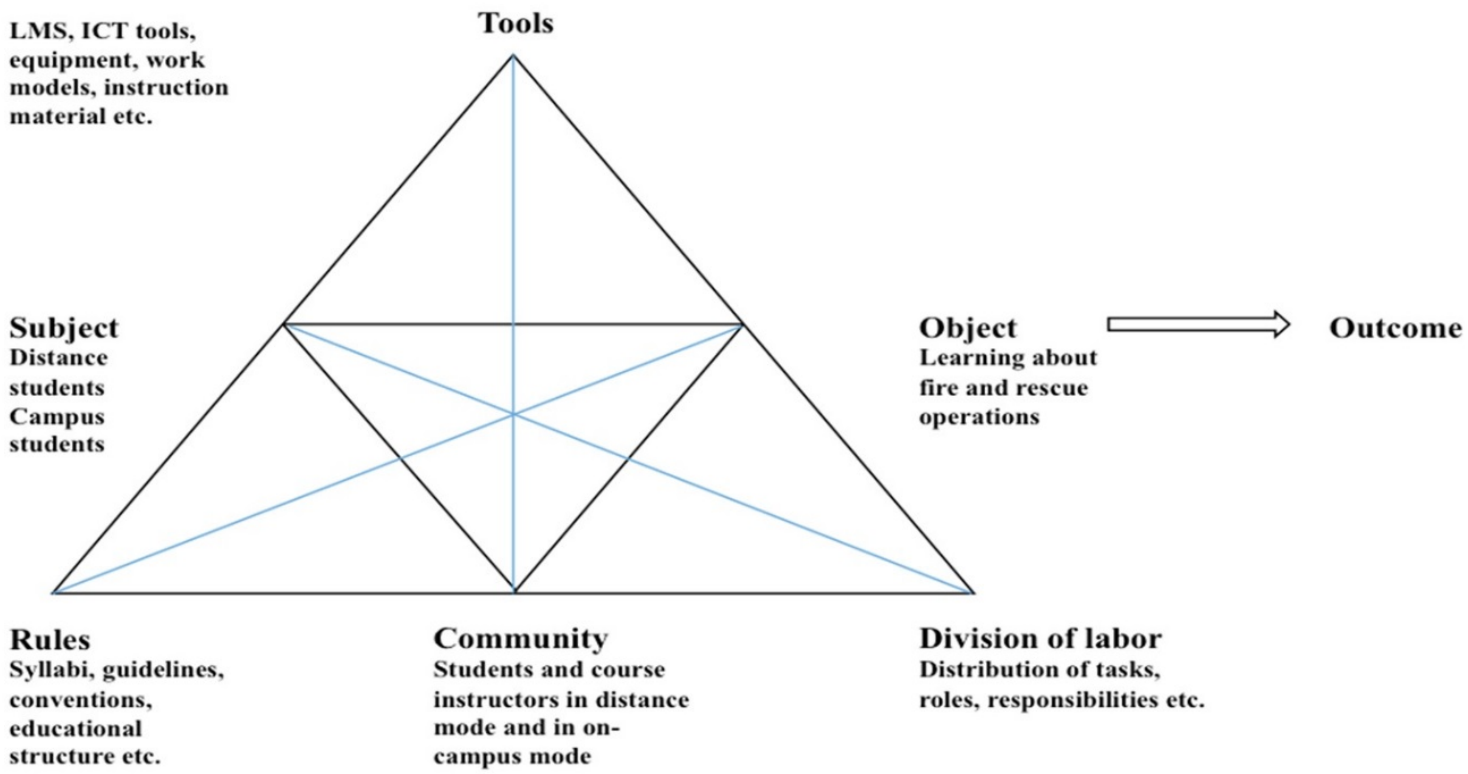

Figure 1. An activity theory model adapted for the analysis of learning processes in firefighter training.

According To Engeström \& Sannino (2011), contradictions cannot be observed directly, but only through their discursive manifestations as articulated by practitioners in words and actions. This analysis is based on Engeström \& Sannino’s (2011) methodological framework for identifying manifested contradictions. Those identified are:

- Dilemmas - expression or exchange of incompatible evaluations.

- Conflicts - take the form of resistance, disagreement, argument and criticism.

- Critical conflicts - facing contradictory motives in social interaction, feeling violated or guilty.

- $\quad$ Double binds - facing pressing and equally unacceptable alternatives in the activity system, with seemingly no way out.

\section{Method}

In view of the focus of this study, i.e. changes in students' learning processes during exercise preparations as well as during the actual exercises, it was decided to use several different data collection methods and include several informant groups. Data on the students' exercise preparations were collected using focus group interviews, while their performance in the exercises was documented through videotaped observations and field notes. In order to enable comparisons between any changes in students' learning processes in the two study modes, campus and distance students in the first and fourth semesters of the programme were included in the study.

Interview data cover a total of seven focus group interviews with students (2-4 students/group), equally distributed between the two study modes and both semesters, a total of 20 students in the age range of 2034 years. The majority of the interviews were conducted on the college campus and the remainder via the institution's web conferencing platform. The interviews, which lasted about 45-90 minutes, were recorded using a digital recorder. After transcription and overall reading, the interview material was processed. The interviews in each study mode were coded and categorised, which generated a large number of empirically-based categories. Using comparative analysis, commonalities between the categories emerged, which made it possible to merge several categories together and eventually define the core key themes presented in the results section. 
Two types of response exercises were observed: Traffic accidents in the first semester and Complex environments in the fourth semester. A response exercise is an exercise where participants are faced with an accident scenario where, on the basis of knowledge and skills acquired during the course, they are expected to rescue injured persons and minimise property damage. The response exercises were performed on the training ground and lasted for 50-70 minutes. Six groups in the first semester and four groups in the fourth semester were observed, a total of 60 students. Each exercise was led by two instructors and the exercises were divided into instructor-led introductions, exercise implementation and instructor-led follow-up sessions. After a comprehensive examination, the recorded film material was transcribed. Dialogues and actions between students and between students and instructors were then coded and categorised, which generated a number of empirically-based categories. Through a comparative analysis of these categories, salient patterns in their interactions could be identified and, in relation to the exercises as a whole, thematically defined and formulated. The generated interview and observation themes were examined based on Engeström's (2001) activity model. The components of this model, such as subject, tools and object, and their relations, e.g. subject-tools, and object-tools, and Engeström \& Sannino’s (2011) methodological framework for identifying manifested contradictions were used to identify any contradictions in the students' learning processes. Upon identification of a number of dilemmas and conflicts, an analysis was made of how the students, interacting with the mediating components of the activity, dealt with these and tried to resolve them. Finally, it was examined whether this interaction contributed to changes in the students' learning processes.

\section{Results}

In this section, the results from interviews and observations with participants in the two training modes are reported. The results of the preparatory phases and exercises phases are presented separately.

\section{Students' voices from the on-campus activity: The preparation phase}

Four themes were identified in the campus students' descriptions of their preparation phase: (i) security through ongoing instruction, (ii) reliance on the instructor, (iii) social communities and informal collaboration for learning and increased motivation, and (iv) a pleasant and undemanding learning process without major challenges. Students' access to ongoing instruction during lectures and tutorials was widely considered to be of crucial importance to learning. The benefits of the teacher-led instruction were described in terms of the instructors' ability to link the training content to reality and to continually give concrete answers to students' questions, which contributed to increased security in the learning process. The interviews also showed that students had a strong reliance on their exercise instructors both as mediators of knowledge and as study organisers. Clear briefings and responses, occupational stories and proven tips and tricks from the instructor were course elements that the students set great store by and consider conducive to learning. A group of fourth-semester students also pointed out the importance of coaching efforts from the instructors, which they believed increased their study motivation.

Furthermore, the learning process on campus was described as collaborative. Closeness to each other and extensive shared time, contributed to the development of informal collaborative actions where spontaneous and more organised work is interwoven with other everyday actions. Some students also pointed out that in order to maintain their motivation for learning, they needed encouraging and supportive fellow students. Since a majority of students lived on the campus area and spent most of their time together, the boundaries between study-related activities and social ones were blurred. The fact that the students met each other every day on campus was considered to strengthen the sense of group community and also to pave the way for initial professional socialisation, which created a sense of incipient professional affiliation. Finally the majority of students on campus described the study pace and the demands made on the students as low. This was seen as frustrating, but at the same time it contributed to perceptions of the learning process as a very pleasant journey. Below, themes and some representative quotes from the campus students are given. 
Table 1

Campus students' preparation on campus. Dominant themes and representative quotes from campus students

\begin{tabular}{ll}
\hline Themes & $\begin{array}{l}\text { Representative quotes from campus students } \\
\text { (C1 = campus student semester 1, C4 = campus student semester 4) }\end{array}$
\end{tabular}

Security through It's great with instructor-led lessons, where they show what each one should do and continuous be responsible for (C1).

instruction If you attend in class, exams and all the exercises, you get all skills (C4). We all have different prior knowledge and everyone has not read in advance. Therefore, instructions and briefings are important so that everyone is aware of what to do during the exercises (C4).

Reliance on
instructor as
mediator of
knowledge and
organiser

\section{Social} communities and informal collaboration for learning and motivation

\author{
It is helpful if the instructor advises us as to where we should seek knowledge - on \\ the internet or at the library. In semester 2 we may understand a little more how \\ and where to seek information (C1). \\ Those who worked a long time in the emergency services are the best. They \\ provide knowledgeable and straight answers. We want to have their knowledge, all \\ their tips and tricks (C4). \\ Some classmates are making their school assignments at once. Others like me, \\ need a teacher who pushes on and say - yes it is good if you do these tasks (C4). \\ We don't sit down at 10 and studying effectively for an hour. There is so much \\ social talk, we drink coffee and hang out (C1). \\ We are sitting in the same boat and will do the same tasks. If the other reads and \\ writes, you're compelled to do it yourself too (C4). \\ In the second semester we had one in the class who was quite proactive. He made a \\ major own training exercise, and it was great. More such initiatives would have \\ been desirable (C4). \\ Here, we get the sense of closeness that it can be at a fire station. We cook and eat \\ and we sleep together, yes, we're together all the time (C1).
}

Pleasurable

learning process

It is not so much of grinding here, you can go to the gym and work out a little, no without challenges stress, just take it easy. Sometimes you get frustrated that you do not have anything to do, but it's also incredibly nice to be here. (C4).

\section{Observations from the on-campus activity: The exercise phase}

Overall, observations of campus student exercises showed a shift from a highly teacher-centered focus in semester 1 to more student-centered features in semester 4 . While the students' actions in the first semester can be generally described in terms of a passive reception of knowledge and a lack of personal responsibility, the fourth-semester students' utterances and actions are more reflective and active. The following themes were identified: (i) performance and focus on details, (ii) knowledge reception and unwillingness to assume responsibility and (iii) reflection and confirmation-seeking.

\section{Performance and focus on details}

The performance in terms of right or wrong, better or worse, was an essential exercise aspect among campus students. This was particularly true of the first-semester students, who also strongly focused on details in the performance of the various stages of an exercise and how these should be carried out in a correct manner. This observation theme was also confirmed by instructors, one of whom expressed that "campus students are more likely to engage in hair-splitting” (Field note).

Knowledge reception and unwillingness to assume responsibility

The actions of the first semester students can be described as passive reception of instructors' directions and assessments. Dialogues between students and instructors were characterised by short instructor questions and student responses, as well as corrective instructions. Few student issues were addressed to the instructor, and comments from observing student groups were few.

Instructor 1: It would have been easier if you had cut the steering wheel. Student 2: Yes, we discussed that. Instructor 1: It should have been wired and ready at once! When you get to 
the point where the roof is off, the cutting machine must be picked up in order to facilitate the removal of the injured from the vehicle. It is always about creating space. Student 5: Yeah, it probably was a bit crowded. Instructor 2: You have to constantly think one or two steps ahead! Instructor 1: We will elaborate on this later, but do not forget this (Observation campus group, first semester).

At follow-up sessions, first-semester students were often unwilling to assume responsibility and referred to unavoidable circumstances which they claimed hampered the implementation of the exercise, such as equipment failures, limited group size and misleading information from other instructors.

Student 4: I could not get at the tire valve with the cutting pliers. There was no groove joint pliers, just a pair of cutting pliers. Instructor 1: Yes, but cutting pliers are the best tool in the world. Student 4: Yes, but the valve was so difficult to get at and I could not reach it with the cutting pliers (Observation campus group, first semester).

\section{Reflection and confirmation-seeking}

Observations in the fourth semester showed that active and reflective approaches were more prevalent among students. During briefings and follow-up sessions, discussions often occurred, initiated by an individual student's reflections on their collaboration and communication, for example about the roles of the members of the responding unit or handover procedures. Several students participated in these discussions with comments and experiences.

Observing student: I noticed that you had not decided in advance who should do what when you got here. Everyone did a bit here and there instead of having their own, individual tasks. Instructor 1: Comments? Student 1: I agree, first we decided to run the big hose there and to get water from there, but due to misunderstandings we ran it from two different directions. Student 2: It is quite inevitable that there will be some discussions in connection with such complicated hose-laying. Observing student: But you knew in advance that there would be that many hoses (Observation campus group, fourth semester).

Furthermore, many of the discussions were characterised by students' quest for knowledge confirmation by the instructors. The questions, which usually concerned practical procedures in rescue responses, were addressed to instructors who, based on their professional experiences, were expected to be able to answer.

Student 3: I just want to clarify something. Say that you need a new point of entry with a new base point, then you need to organise it differently, right? Instructor 1: Yes, you mean, if we have to enter the building here? Student 3: Yes. Instructor1: Yes, then you cannot get someone from here, you must wait until you have an additional unit available. Student 3: Yes. Student 5: Can we talk about whether the hoses need to be extended? (Observation campus group, fourth semester).

With these findings from the on-campus activity in mind, the distance activity is now examined.

\section{Students' voices from the distance activity: The preparation phase}

In the interviews with the distance students, the following five themes were identified: (i) anonymity and uncertainty, (ii) self-directed learning, (iii) efficiency-related studies, (iv) knowledge-oriented communities and (v) gradual adaptation to prevailing training norms and requirements.

Among the distance learners, there was a clear perception that instructors' online presence was very limited. Few online lessons, limited support and poorly updated instructors and online instructions were examples of conditions that contributed to an anonymous existence for distance students relative to their instructors, and to uncertainty in relation to the course content and expected learning outcomes. Several distance students reported frustration during the initial phase of the training, caused by the lack of instructor availability and ambiguities in training instructions. This created tensions in relation to the generally high ambitions among these students to be well prepared for the exercise sessions. Furthermore, interviews showed that over time, and as a kind of adaptation to the environmental conditions, distance students developed self-directed strategies, in which they took command of their own learning process 
through goal-targeted and problem-solving oriented actions. For example, as they required clear instructions in order to increase their own control over their studies, they tended to create alternative, more suitable online forums to facilitate communication within the groups.

The interviews also yielded a picture of the online-based learning process as an activity which was largely characterised by efficiency thinking. In the digital learning environment they paid attention primarily to course content and examination requirements, while social aspects, in-depth topic dialogues and questions addressed to the instructor tended to be deferred to the meetings on campus. Time constraints limiting the opportunities for interaction within the student groups, and the students' strong views on the affordances and constraints of the offered technologies, set the bar for and shape their group-oriented study strategies that evolved over time. Therefore, in order to enhance the effectiveness of their studies, they preferred individual tasks, and strived to develop a clear division of labor and to find their own study solutions. For example, in performing group tasks, they allocated responsibility among themselves and preferred to use asynchronous written forums, particularly social media, which they considered more time-efficient and effective than synchronous communication forums. In the online interaction vacuum resulting from low instructor presence, the group fulfilled a significant knowledge-generating function, where the students could both give and receive support and where their different professional experiences, especially from the emergency services, constituted specific knowledge resources. Finally, as with the campus students, the distance learners described the course requirements and the study pace as low. This meant that their motivation for engaging in the online preparation phases decreases as they perceived that the main course content could be acquired during the instructor-led exercise lessons on campus.

Table 2

Distance students' preparation on campus: Dominant themes and representative quotes

\begin{tabular}{ll}
\hline Themes & $\begin{array}{l}\text { Representative quotes from distance students } \\
\text { (D1 = Distance student semester 1, D4 = distance student semester 4) }\end{array}$ \\
\hline $\begin{array}{l}\text { Anonymity } \\
\text { and }\end{array}$ & $\begin{array}{l}\text { Sometimes when you call an instructor - who are you? They're trying to put you in a } \\
\text { uncertainty }\end{array}$ \\
$\begin{array}{l}\text { We've had some problems with poorly updated instructors D4). } \\
\text { If we have missed or misunderstood something, then there is no one who is checking up } \\
\text { or pushes us in the right direction (D1). }\end{array}$
\end{tabular}

Self-directed When I feel the frustration, there is no instructor who comes along and says - that's the learning way you should do it. But usually I turn the frustration so that I actually learn something (D1).

Since we wanted to perform well on the exercises, we prepared a little too much. But on the other hand it was pretty good (D1).

It is good to have short and distinct classes and a clear plan where I can see what is required of me. Then I can plan the day and basically the whole course (D4).

I created a facebook group for the entire class for anyone wondering about a task. And there are many in the class that uses it (D4).

Efficiency- We talk almost just school assignments online. It's awkward when six people will take related turns talking. So social stuff gets a little cumbersome (D1).

studies Most of us have jobs and kids, therefore we agree to do the work time efficiently. (D1). We have our dear face-book. It is a very quick way to get in touch with all (D1). We usually meet in our online classroom and discuss what should be done. Then we distribute the responsibility for the tasks to make it go faster and smoother (D4).

Knowledge- Everyone was really confused and then we gathered the group and checked out how oriented each one had understood the information. So, we turn to each other all the time. First, communities you take it with the group, and then the class via face-book and if nobody has any idea, then you look for an instructor (D4).

In our group, we have an ambulance nurse and a fire engineer, and they have been important resources that we have learned a lot from (D4).

Adaptation If you've read the theory properly at home, notice that you do it again when you come to to prevailing campus. So usually you become prepared on the spot without having done too much at norms and home (D4).

requirements 


\section{Observations from the distance activity: The exercise phase}

Taken together, the observations of the exercises of the distance groups showed a more student-centered orientation compared to that of the campus groups, a difference which, however, was most marked among first-semester students. These students were highly performance-oriented and self-critical. Furthermore, the exercises of the distance groups were characterised by reflective and confirmation-seeking actions. The following dominant themes were identified: (i) performance and self-criticism, and (ii) reflection and confirmation-seeking.

\section{Performance and self-criticism}

Like the first-semester campus students, the first-semester distance students also focused on exercise performance. However, they took a more active role in the dialogue with the instructors where they selfcritically analysed a number of problems caused by inefficient and sub-optimal actions.

Instructor 1: Let's begin with reflections from group 2. Student 1: It was fun, the exercise went very well. Student 2: Initially, it was a bit chaotic at the accident scene. It was not clear enough where I wanted the fire vehicle and the barrier. So it took a few extra minutes that we could have saved. Instructor 1: Yes, you lost a little time there. Anything else? (Observation distance group, first semester).

\section{Reflection and confirmation}

The distance students' actions at briefings and follow-up sessions could be described as reflective and confirmation-seeking. Their reflections, which usually concerned consequences and ambiguities resulting from the choices made during the rescue operations, often led to discussions in which several students were involved.

Student 3: It is better to send in new smoke divers and retain the protection team until it needs to be replaced. Student 1: Yes, we thought so. Student 4: Otherwise, a protection team which has 120 bars left may be sent in for two minutes of smoke-diving and then they will have to get out again. Student 3: Exactly. Student 1: Then there would be a handover with several stages that might go wrong and information that may be missed. So I really don’t know what happened the first time (Observation distance group, fourth semester).

As in the exercises of the campus groups, confirmation-seeking elements were common during the exercises. For the first-semester students, this was shown by the many questions addressed to the instructor before and after the exercises. In the fourth semester, students preferred to direct their questions to the student group, which led to problem-solving discussions and confirmatory comments.

Student 5: Could we have been better at sketching up the areas when we arrived? Student 3: It was a good thing that you did that right at the start. Student 5: It feels like it's the easiest way to report where we have searched. Student 6: I also felt that, because we could look at the sketch before we went in and it was a pretty good match (Observation distance group, fourth semester).

\section{Analysis}

The analysis shows that from a student perspective, no contradictions in terms of discursive manifestations can be identified in the campus activity. Rather, there seem to be strong relationships between the various components that constitute important cornerstones in the campus activity. This is particularly true of the relationships between object-instructor (1), object-community (2) and between object and tools (3) (see Figure 2). More specifically, it appears that the ongoing face-to-face teaching based on instructors' proven expertise; a strong belief that learning is primarily about being able to perform practical actions in the right way; and social and knowledge support from the group are the most important incentives in the campus students' learning processes.

When it comes to division of responsibilities and roles, salient patterns in the analysis indicate a student role during the initial part of the training that is characterised by relatively passive reception of 
knowledge and transfer of responsibility from student to instructor. However during the latter part of the training, particularly during the implementation of exercises, it appears that the responsibility in the activity is shifted slightly from the instructors to the students, as demonstrated by the larger space in dialogues given to the students' experiences and views. The cause of this change in campus students' learning processes is likely attributable to the fourth-semester students having acquired sufficient professional experience to be able to take greater responsibility for their learning after several semesters of teaching, including one semester of practice.

In the distance activity, a number of contradictions have been identified which affect the distance students' learning processes. However the contradictions, here interpreted and visualised as discursively manifested dilemmas and conflicts, appear to be most dominant among the students in the first semester of the programme, while the students in the fourth semester have found their own solutions and at the same time adapted their strategies to current teaching norms and course requirements. Figure 2 shows the two parallel training modes as two activities and the contradictions and strong relationships identified.

\section{On-campus activity}

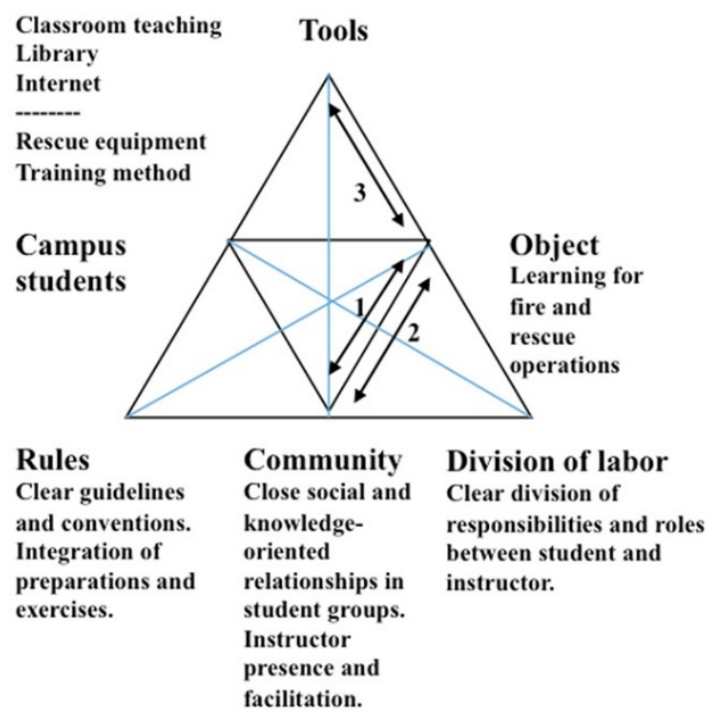

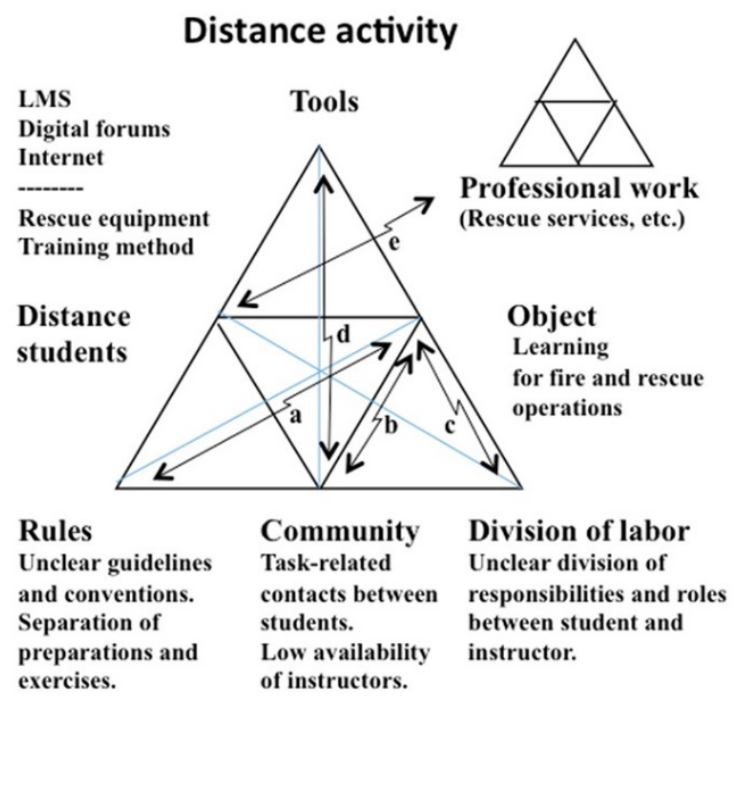

Figure 2. The two parallel training modes as two activities, and the contradictions and strong relationships identified.

The following contradictions have been identified in the distance activity:

a) Students' conceptions of the object - unclear online guidelines as to the relationship between preparations and exercises (rules): First-semester students in particular, seem to have high ambitions to be well prepared theoretically in order to be able to perform at their best during the few exercise meetings. Unclear online guidelines as to what is expected regarding theoretical preparation levels and practical exercise performance create a tension that from a student perspective can be interpreted both as a dilemma that results in uncertainty, and as a conflict that is expressed through their criticism of the prevailing conditions.

b) Students' conceptions of the object - shortcomings regarding the instructors' presence and facilitation of the students' online learning (community). The aforementioned uncertainty among the first-semester students does not seem to decrease. Instead it appears to be reinforced due to low instructor presence and shortcomings related to their support and facilitation of the students' learning processes. Students' accounts of often being left to their own devices when working with problem-solving and in online discussions can be interpreted as a dilemma which creates a sense of uncertainty and anonymity. It can also be viewed as a conflict, as they tend to criticise the lack of instructor support. 
c) Students' conceptions of the object - unclear division of responsibilities and roles between students and instructors online. Shortcomings involving unclear expectations regarding the students' and instructors' responsibilities in the online collaboration are interpreted as a dilemma which reinforces students' uncertainty during the preparation phase.

d) Students' own learning goals - digital technologies offered at the college (tools). Distance students' intentions to communicate and share knowledge in groups are to some extent hampered by the perceived constraints of the asynchronous and synchronous technologies offered by the LMS and the web conferencing platform. This is interpreted as a dilemma that hampers deeper collaboration and social interaction.

e) Students' commitment in the online preparation phase - their competing commitments in other activities. Since a majority of the distance students are working alongside their studies, the extent and shapes of their communication and collaboration are affected. This is seen as a dilemma as their study collaboration must be adapted to these students' duties at work.

In the light of these defined dilemmas and conflicts, questions arise concerning how the distance students deal with these and what strategies and solutions they develop over time. The analysis shows that in comparison with the campus students' instructor-controlled and stable learning processes, the distance students change their online communication and collaboration actions and strategies, and develop more self-directed and learner-centered approaches. Their changing actions and strategies are evidenced in their streamlining of the online collaboration through increased division of labor, their focus on knowledgerelated communication and in their ways of using social media for quick access to information. Selfdirected and learning-centered approaches are evidenced in the way they create alternative online communication paths and sort out ambiguities independently of their instructors with the support of more knowledgeable peers with professional experience bringing in knowledge from outside. Thus, despite shortcomings in the training programme's online learning environment, the analysis shows that the distance students assume a great deal of responsibility for planning their learning and acquiring knowledge during the preparation phase. Their self-directed and learner-centred approaches also seem to carry over to the exercise phase, where they tend to act in a more independent, problem-oriented and selfcritical manner compared to the campus students. It would appear that, compared to the campus students, the distance students are not as dependent on their instructors' guidance and control of their learning. Instead they rely to a large extent on the knowledge they have acquired on their own during the preparation phase. This is an indication that extended periods of online-based exercise preparations may be a good alternative to campus-based preparations where theoretical and practical elements are integrated.

In the longer perspective however, the prevailing training conventions as regards teaching and learning, performance requirements and training pace seem to have a slightly negative impact on the distance students' attitudes and commitment during the online preparations. It appears that their motivation for maintaining an active and self-directed approach to learning drops when they discover that the demands made on them in practice sessions are not very exacting, that the study pace is fairly low and that a great deal of their knowledge acquisition can be done during the meetings on campus in instructor-led sessions. In other words, there is a kind of normalisation over time whereby the distance students' learning processes to some extent tend to become more similar to those of the campus students, i.e. the instructors' responsibilities, guidance and control become more important and the distance students adapt their actions and strategies to the contextual conditions they perceive as being part of the training programme.

\section{Discussion, conclusions and further implications}

The comparison of the learning processes in the two activities, campus mode and distance mode, shows that the active learning communities discussed by Olofsson (2007) and Shea (2006) develop in both study modes, but have different characteristics and degrees of access to support from instructors. On the one hand there are the learning communities on campus, described by the students as teams similar to those found in the rescue services with constant social interactions and fellow students and instructors as motivational and regulating agents in the learning processes. On the other hand, there are the communities in the technology-supported distance activity which appear to be largely centered around self-directed and knowledge-oriented interactions. The clear link between instructors' presence, effective instructional 
design, directed facilitation and students' sense of community and learning which has been reported in several studies (e.g., Shea, 2006), can therefore not be identified in this study. On the contrary, and in line with the activity theory's focus on contradictions as driving forces of change in processes and activities, it is demonstrated that learner-centered communities can develop when distance students, interacting with mediating tools and resources, resolve dilemmas and conflicts encountered. The dilemmas and conflicts identified in this study are not unique but are similar to ones found in several other studies, for example that there may be shortcomings in online environments as regards unclear division of labor and online guidelines (Choi \& Kang, 2010; Dippe, 2006), instructors' online support and facilitation (Olofsson, 2007; Holmgren, 2014, Shea, 2006) and constraints in offered digital technologies (Margaryan et al., 2008). It has also been shown in other studies that distance students may experience a sense of anonymity and uncertainty in the online environment (Paechter \& Maier, 2010) and that competing commitments in other activities may prevent them from pursuing active studies (Antoniadou, 2011; Liu \& Schwein, 2006). However a significant finding in this study is that the distance students fairly quickly identify, and try to find solutions to, contradictions they perceive as impediments to efficient and effective learning during the preparation phase. In the light of the distance students' strong motives for being theoretically well prepared for exercises (cf. Liu \& Schwen 2006), these contradictions could also be described as catalysts that influence and change their learning processes through alternative learning actions and strategies. For example the absence of instructors as mediating resources in the online environment is compensated for by other mediating resources, such as a carefully planned use of technologies (Andrews \& Tynan, 2012; Conole et al., 2008; de Laat \& Conole, 2008) and markedly knowledge-based and experience-based group interactions (Maxfield \& Fisher 2011). Compared to the campus activity, the dilemmas and conflicts and the ways these were handled in the distance activity may therefore in some sense be said to have contributed to an expansive learning (Engeström, 1993) which developed among the distance students. Their increased responsibility and ability when it comes to seeking and processing information and solving study problems with support from the group, seem to indicate that the objects and motives of the distance activity are under constant negotiation and review, rather than primarily defined by the instructors, as in the campus activity.

The tendencies towards less active approaches online, which can be traced over time among the distance students in this study, suggest that contextual aspects gradually affect the distance activity in the direction of the exercise and instructor-centered focus that characterises the campus activity (Kirkwood, 2009; Price \& Kirkwood, 2010). Most likely, this change can be understood in the light of the instructors' modeling function (Sharpe et al., 2009) and, as shown in the analyses, the institutional conventions of learning and requirements (Kirkwood, 2009). Thus the incipient expansive learning process among students at the beginning of the training course is to some extent normalised towards the more adaptiveoriented type of learning often found among students at the end of the training course and which characterises the traditional campus activity (cf. Holmgren, 2014).

The conclusions drawn from this study can be summarised in four themes:

(i) The activity theory and its concept of contradiction has provided a useful framework for understanding changes in learning processes when an innovative component such as technologysupported distance learning is introduced into an established training practice. The theory's comprehensive account of several components of the activity and their relationships has contributed to highlighting dilemmas and conflicts from a student perspective as well as the ways in which they deal with these. Furthermore, the theory's account of the historical dimensions of activities, has increased the understanding of how institutionally embedded norms and conventions of teaching and learning may be influential agents in learning processes in exercise training courses.

(ii) When technology-supported learning is introduced and used in exercise training courses, students may face several dilemmas and conflicts related to the lack of instructor presence and facilitation, ambiguities involving division of labor and guidelines, constraints in the technologies offered and competing commitments alongside their studies.

(iii) Dilemmas and conflicts arising in exercise technology-supported training courses, can be a driving force for changes in students' learning processes. As shown in this study, these changes may result in students developing learner-centered strategies and actions during both exercise preparations and during the actual exercises. However in the longer term, students need an online-based 
environment designed for collaborative learning and present and active instructors who can support the students' learning during all phases of the training.

(iv) Institutional teaching and learning norms and conventions from traditional campus courses may counteract and have normalising effects on learning processes in technology-supported distance training. For this reason, it is essential that both the instructors and program management teams develop an organisational, pedagogical and digital readiness through reflections on, and reassessments of, collective and personal assumptions regarding training structures, teaching and learning. In order for technology-supported distance learning to become a catalyst for change in traditional professional training courses, rather than a mere replica of traditional face-to-face learning on campus, it is also important that course directors and instructors explore the unique opportunities for knowledge interactions offered by online learning environments.

While the strength of this study might be its contextual and change-oriented perspectives, it also has its limitations. Observations of online-based and classroom-bound teaching, and more student voices would probably have given deeper insights into these kinds of learning processes.

Finally, in the light of these conclusions, several questions arise. How should a technology-supported distance training be designed in which both student initiative for learning and instructors' proven expertise can be leveraged? How should technologies be designed and used in ways that will benefit both enhanced collaborative learning and serve as a bridge between theoretical preparation and exercise implementation? What can a training course as a whole inclusive campus modes learn from the contradictions and changes in the distance mode indicated in this study? Any future work addressing these issues will, however, require a research process that includes both a commitment to change among the training program's stakeholders and long-term, close collaboration between researchers and practitioners.

\section{References}

Andrews, T., \& Tynan, B. (2012). Distance learners: Connected, mobile and resourceful individuals. Australasian Journal of Educational Technology, 28(4), 565-579. Retrieved from http://ascilite.org.au/ajet/submission/index.php/AJET/issue/view/10

Antoniadou, V. (2011). Using Activity Theory to understand the contradictions in an online transatlantic collaboration between student-teachers of English as a Foreign Language. ReCALL, 23(3), 233-251. http://dx.doi/10.1017/S0958344011000164

Campbell, M., Gibson, W., Hall, A., Richards, D. \& Callery, P. (2008). Online vs. face-to-face discussion in a webbased research methods course for postgraduate nursing students: A quasi-experimental study. International Journal of Nursing Studies 45(5), 750-759. http://dx.doi.org/10.1016/j.ijnurstu.2006.12.011

Choi, H., \& Kang, M. (2010). Applying an activity system to online collaborative group work analysis. British Journal of Educational Technology, 41(5), 776-795. http://dx.doi.org/10.1111/j.1467-8535.2009.00978.x

Collins, J. \& Pascarella E.T (2003). Learning on campus and learning at a distance: A randomized instructional experiment. Research in Higher Education, 44(3), 315-326. http://dx.doi.org/10.1023/A:1023077731874

Conole, G., de Laat, M., Dillon, T., \& Darby, J. (2008). ‘Disruptive technologies’, ‘pedagogical innovation’: What's new? Findings from an in-depth study of students' use and perception of technology. Computers \& Education, 50(2), 511-524. http://dx.doi.org/10.1016/j.compedu.2007.09.009

de Laat, M. \& Conole, G. (2008). Patterns of students’ use of networked learning technologies. Proceedings of the 6th International Conference on Networked Learning (pp. 86-94). Retrieved from http://networkedlearningconference.org.uk/past/nlc2008/abstracts/PDFs/deLaat_86-94.pdf

Dippe, G. (2006). The missing teacher: Contradictions and conflicts in the experience of online learners. In Proceedings of the Fifth International Conference on Networked Learning 2006, Lancaster: Lancaster University. Retrieved from http://halshs.archives-uvertes.fr/docs/00/19/03/03/PDF/Gunther-Dippe-2006.pdf

Donavant, B. W. (2009). The new, modern practice of adult education online instruction in a continuing professional education setting. Adult Education Quarterly, 59(3), 227-245. http://dx.doi.org/10.1177/0741713609331546

Engeström, Y. (1987). Learning by expanding. An activity theoretical approach to developmental research. Helsinki: Orienta-Konsultit Oy.

Engeström, Y. (1993). Developmental studies of work as a test bench of activity theory: The case of primary care medical practice. In S. Chaiklin, \& J. Lave (Eds.), Understanding practice: Perspectives on activity and context (pp. 64-103). Cambridge: Cambridge University Press.

Engeström, Y. (2001). Expansive learning at work: Toward an activity theoretical reconceptualization. Journal of Education and Work, 14(1), 133-156. http://dx.doi.org/10.1080/13639080020028747 
Engeström, Y., \& Sannino, A. (2011). Discursive manifestations of contradictions in organizational change efforts: A methodological framework. Journal of Organizational Change Management, 24(3), 368-387. http://dx.doi.org/10.1108/09534811111132758

Holmgren, R. (2014). Firefighter Training in Sweden: from face-to-face learning in training grounds to distance learning - A challenge for exercise instructors? Technology, Pedagogy and Education. http://dx.doi/10.1080/1475939X.2014.968197

Kaptelinin, V. \& Nardi, B. (2006). Acting with technology: Activity theory and interaction design. Cambridge, MA: MIT Press.

Karasavvidis, I. (2009). Activity Theory as a conceptual framework for understanding teacher approaches to information and communication technologies. Computers \& Education, 53(2), 436-444. http://dx.doi.org/10.1016/j.compedu.2009.03.003

Kian-Sam, H., \& Lee, J. A. C. (2008). Postgraduate students' knowledge construction during asynchronous computer conferences in a blended learning environment: A Malaysian experience. Australasian Journal of Educational Technology, 24(1), 91-107. Retrieved from http://ascilite.org.au/ajet/submission/index.php/AJET/issue/view/37

Kirkwood, A. (2009). E-learning: You don't always get what you hope for. Technology, Pedagogy and Education, 18(2), 107-121. http://dx.doi.org/10.1080/14759390902992576

Liu, X., \& Schwen, T. M. (2006). Sociocultural factors affecting the success of an online MBA course. Performance Improvement Quarterly, 19(2), 69-92.

Margaryan, A., Nicol, D., Littlejohn, A., \& Trinder, K. (2008). Students' use of technologies to support formal and informal learning. In J. Luca \& E. Weippl (Eds.), Proceedings of World Conference on Educational Multimedia, Hypermedia and Telecommunications 2008 (pp. 4257-4266). Chesapeake, VA: AACE. Retrieved from http://www.editlib.org/p/28976/

Maxfield, R.J., \& Fisher, J. R. (2011). Employing critical reflection in an online emergency services course. Journal of Homeland Security Education 1(1), 26-40.

Murphy, E., \& Rodriguez-Manzanares, M. A. (2008). Using activity theory and its principle of contradictions to guide research in educational technology. Australasian Journal of Educational Technology, 24(4), 442-457. Retrieved from http://ascilite.org.au/ajet/submission/index.php/AJET/issue/view/34

Myndigheten för Samhällsskydd och Beredskap, (Swedish Civil Contingencies Agency). (2002). Curriculum for SMO (Accident Prevention Training Course). Karlstad, Sweden: Publikationsservice.

Olofsson, A. D. (2007). Participation in an educational online learning community. Journal of Educational Technology \& Society, 10(4), 28-38.

Paechter, M., \& Maier, B. (2010). Online or face-to-face? Students' experiences and preferences in e-learning. The Internet and Higher Education, 13(4), 292-297. http://dx.doi.org/10.1016/j.iheduc.2010.09.004

Price, L., \& Kirkwood, A. (2010). Technology enhanced learning-where’s the evidence. Curriculum, technology \& transformation for an unknown future. Proceedings ascilite Sydney, 772-782. Retrieved from http://ascilite2012.org/conferences/sydney10/procs/Price-concise.pdf

Redecker, C., Ala-Mutka, K., Bacigalupo, M., Ferrari, A., \& Punie, Y. (2009). Learning 2.0: The impact of Web 2.0 innovations on education and training in Europe. Final Report. European Commission-Joint Research CenterInstitute for Porspective Technological Studies, Seville. Retrieved from ftp://ftp.jrc.es/pub/EURdoc/EURdoc/JRC55629.pdf

Sharpe, R., Beetham, H., Benfield, G., DeCicco, E., \& Lessner, E. (2009). Learners experiences of e-learning synthesis report: Explaining learner differences. Retrieved from https://mw.brookes.ac.uk/display/JISCle2f/Findings

Shea, P. (2006). A study of students' sense of learning community in online environments. Journal of Asynchronous Learning Networks, 10(1), 35-44.

Yang, D. F., Catterall, J., \& Davis, J. (2013). Supporting new students from vocational education and training: Finding a reusable solution to address recurring learning difficulties in e-learning. Australasian Journal of Educational Technology, 29(5), 640-650. Retrieved from http://ascilite.org.au/ajet/submission/index.php/AJET/issue/view/54

Corresponding author: Robert Holmgren, robert.holmgren@umu.se

Australasian Journal of Educational Technology (c) 2015.

Please cite as: Holmgren, R. (2015). New ways of learning to fight fires? Learning processes and contradictions in distance and on-campus firefighter training in Sweden. Australasian Journal of Educational Technology, 31(2), 220-234. 